\title{
Towards a Conditional Model of Coalition Behaviour*
}

\author{
BAS DENTERS
}

Twente University of Technology, Enschede, The Netherlands

\begin{abstract}
This is an attempt to formulate a conditional model of coalition formation. Predictions from this model are tested against data on coalition formation in Dutch local government in 1982. Starting from a simple model of the behaviour of party politicians, it is assumed that the coalition behaviour of parties depends on the competitiveness of the (local) political system. The choice of a coalition strategy (minimizing size, minimizing policy range or proportional representation) is contingent upon two dimensions of the competitiveness of local politics. These are the amount of electoral volatility and the extent to which local election results follow national trends. Our conditional theory predicts different coalition behaviour in polities differing with regard to these two factors. Though the hypothesis was falsified, a more detailed analysis showed that (local) political competitiveness did make a difference in the choice of at least some of the coalition strategies. These differences, moreover, were in line with what was to be expected from the theoretical model.
\end{abstract}

In the literature on formal theories of coalition formation, a number of distinct theories has been formulated. These theories are normally grouped in two 'families', differing with regard to the strategy adopted by parties forming coalitions. First, there are theories assuming that parties employ a size criterion in their choice from alternatives. According to these theories only coalitions of a minimal size will be formed. ' Secondly, there are theories which assume that parties strive for a minimization of the ideological or policy range of a coalition. ${ }^{2}$

But to state these distinct (groups of) coalition theories, is to beg several questions. Why should a party opt for one criterion rather than another? Is there one universal coalition theory which is valid in all party-political contexts, or are coalition theories in some sense conditional? These questions become even more pressing in the light of the empirical evidence gathered in such eminent studies as De Swaan (1973) and Laver and Taylor (1973). Their tests of coalition theories show that the predictive value of theories varies strongly from one country to another.

*The author thanks Harry Daemen, Einte Elsinga, Nico Mol, Jacques Thomassen and three anonymous referees for their helpful comments and suggestions. 
This again raises several questions. What makes one country different from another? Which characteristics of these countries induce parties to behave in a different way? In this article we will propose and test a conditional model of coalition formation in which it is assumed that the coalition behaviour of politicans depends on relevant conditions of their party-political environment. What are to be considered relevant conditions will be decided on the basis of a simple model of party competition.

\section{A MODEL OF PARTY COMPETITION}

The central assumption in our simple model of party competition is borrowed from Breton (1974) and Frey and Lau (1968). They assume that politicians try to maximize such values as the income, power, prestige and related benefits which come from political office. In doing so, politicians are confronted by a number of constraints. One of these, according to these authors, is an electoral constraint. Under certain circumstances politicians have to compete for the electorate's favours in order to attain or retain office. In the theory of public choice it is generally assumed that the competition for electoral support takes the form of offering a policy-mix maximizing the party's share of the vote. As Downs (1957, 105-9) pointed out, parties have to be consistent and reliable, to a certain extent, with regard to their election-time promises, if they wish to be electorally successful in the future. This need for consistency and reliability will vary with the degree to which an electoral constraint is operative. In other circumstances, however, the electoral constraint is less restrictive, and politicians can, without seriously damaging their election result, behave in a way that is directly conducive to their ultimate goals.

An electoral constraint is operative only as long as parties believe that their behaviour actually affects results at the poll. As it is our aim to test the hypotheses to be formulated against empirical evidence on local government coalition formation, we shall concentrate on the local level. In our view there are at least two reasons which might induce local politicians to consider the outcome of the election as an event they cannot influence.

First, voters may have developed rather stable voting habits. This is reflected in a low rate of political volatility. Political volatility refers to the variations over time of the party's share of the total vote. This concept of volatility can be considered as one aspect of electoral competition. ${ }^{3}$ Constancy of voting shares over a longer period of time, reflecting rather stable party affiliations, may induce politicians to believe that their behaviour does not affect the outcome of the election.

Second, in the literature on local elections, the idea that local factors have only a marginal impact at the polls, and that the outcome is largely attributable to national trends, is widespread (see for instance Dunleavy, 1980, 136-7). The extent to which a local election is 'nationalized' can be considered as a second factor determining the presence of an electoral constraint on party behaviour. ${ }^{4}$

Dichotomizing and cross-classifying electoral volatility and the 'nationalization' of local elections," provides us with four local political system types (Fig. 1). We will refer to electoral systems having a low rate of volatility as low-volatility (as against high-volatility) electoral systems. Systems having a high degree of nationalization will be labelled 'nationalized' as opposed to 'localized' systems. 


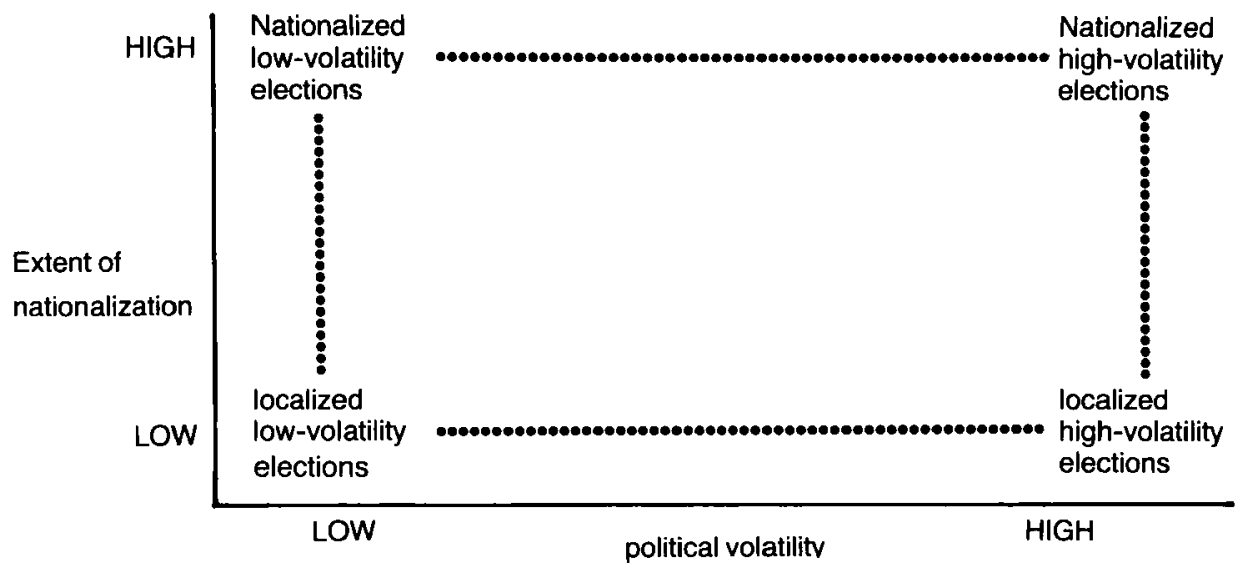

Fig. 1. A typology of local electoral systems

In the next two sections we will argue that the choice of coalition strategy by parties depends on the nationalization and volatility of electoral systems. On the basis of our simple theoretical model we will hypothesize that size-principle theories are likely to predict better in nationalized high-volatility electoral systems while policy-range theories perform better in localized high-volatility systems. Furthermore, it will be argued that neither size-principle nor policy-range theory is likely to predict coalition behaviour accurately in low-volatility electoral systems. We shall also develop a coalition theory which is able to account for coalition behaviour under these circumstances.

\section{SIZE-PRINCIPLE AND POLICY-RANGE THEORIES ${ }^{6}$}

Notwithstanding several important differences, size-principle and policy-range theories have at least one thing in common. Both are based on the assumption that coalition formation is a unique event. This assumption is neither self-evident nor inconsequential. Government formation typically is a recurrent event. And the behaviour of actors in a sequence of games (a so-called supergame) ${ }^{7}$ can differ radically from that of players in a single game (Taylor, 1976). In a sequence of games, rational actors will adopt strategies maximizing their pay-offs in the supergame, rather than in each consecutive game separately. In this context it may be rational to forgo short-term benefits to incur larger future benefits. For instance, while it may be profitable to exclude one or more major parties from the coalition in the short run, this strategy may be counterproductive in the long run when other parties retaliate by excluding you from all future coalitions.

Whether actors opt for such a long-term strategy depends, among other things, ${ }^{8}$ on the turbulence of the environment. A major source of turbulence in the partypolitical environment in which coalition games are played is electoral volatility. The electoral strength of a party is likely to be a major determinant in the distribution of pay-offs in coalition games (De Swaan, 1973, 155). So high volatility makes future 
benefits highly uncertain. The rational reaction to this uncertainty is to discount future benefits or to disregard these altogether. Therefore high volatility increases the inclination of parties to pursue short-term strategies.

Therefore, even though coalition formation is best conceived of as a supergame, under highly uncertain conditions parties will act 'as if' they were playing a single game. Under these specific circumstances (high uncertainty, for example high volatility), size-principle and policy-range theories can provide accurate predictions. For this reason we hypothesize that in high-volatility electoral systems size-principle and policy-range theories will predict coalition behaviour more accurately than in low-volatility electoral systems.

Are size-principle coalitions likely in all high-volatility electoral systems, or are they more likely to occur in either nationalized high-volatility or localized highvolatility systems? Coalition theories based on the size principle assume that the stake of the game is the number of seats. This is a 'fixed prize': seats for one party reduce the number of seats available for the other parties. ${ }^{9}$ Assuming that the sole objective of parties is the maximization of seats in government, as is done in size-principle theories, a coalition of minimum size will be formed.

When will parties make the maximization of seats their sole objective? In our theoretical model politicians are motivated by a desire to maximize the rewards of political office. Seats in government are likely to be highly attractive in this respect. If no electoral constraint is operative, politicians can ignore policy considerations and will concentrate on their ultimate goal. In nationalized high-volatility systems, one condition for the presence of an electoral constraint is not fulfilled. Though volatility is relatively high, fluctuations appear to be largely attributable to national political factors. Therefore, in these systems parties are likely to concentrate on the maximization of seats. Size-principle theories probably will predict coalition formation accurately in this specific context.

In localized high-volatility elections, however, the conditions for the presence of an electoral constraint are fulfilled. Under these conditions parties will try to influence the direction of local voting shifts in their favour by competing for electoral support. Earlier, we argued that under these circumstances the need for consistency and reliability is high. This need will affect the willingness of parties to enter particular coalitions.

Under these circumstances coalitions of parties proposing rather similar policies are more likely to form than alliances between parties proposing radically different policies. In coalitions of a minimal or limited policy range it is relatively (as compared with more heterogeneous alliances) easy to implement policies akin to those proposed by all of its members. These coalitions are likely to minimize the damage post-election compromising is bound to inflict upon the credibility of coalition parties. For this reason it seems warranted to expect that policy considerations dominate the process of coalition formation in localized high-volatility systems: parties will prefer coalitions with partners having relatively homogeneous policy preferences to more heterogeneous coalitions.

The idea of minimizing the ideological heterogeneity of a coalition, operationalized in the minimization of the coalitions' ideological or policy range, is at the core of policy-range theory. Therefore we hypothesize that this theory is likely to predict coalition behaviour particularly accurately in localized high-volatility electoral systems. 


\section{PROPORTIONAL REPRESENTATION THEORY}

As we hypothesized in the previous section both policy-range and size-principle theory are likely to be particularly appropriate in high-volatility electoral systems. What coalitions will form under more stable conditions?

First, it should be noted that a stable environment (i.e., low-volatility rates) increases the likelihood that politicians will calculate the costs and benefits of alternative coalition strategies over a longer period. The outcome of such a calculation might show that in the long run a long-term strategy, based on cooperation between, rather than on the exclusion of, major parties is profitable. In systems having a lower rate of volatility, coalitions, containing either unnecessary parties or parties adding to the coalition's policy range, may be formed. But this raises the question what benefits come from grand coalitions.

Arend Lijphart $(1977,27)$ has argued that excluding major parties from coalitions may be unwise in countries lacking a homogeneous and pragmatic political culture. Prudent political leaders motivated by a desire for the stabilization of the political system in these countries will tend to form grand coalitions.

The desire to stabilize a country, however, is a motive that does not fit very well in our theoretical model in which it was assumed that politicians try to maximize the rewards of office. Stabilization of the political system may be an honourable goal to pursue. But behaviour having this effect/function fits in our model only in as far as it can be shown to be individually rational for politicians, given the goal of maximization of the rewards of office.

Are there any individual benefits for politicians associated with the formation of grand coalitions? We think there are! A long-term agreement in which the division of seats in government among the major parties is settled, might be advantageous for two reasons. In the first place, the sum of the benefits from such an agreement over time might exceed the benefits from short-term strategies based on the exclusion of major parties. Secondly, certainty on important future benefits and the non-conflictive style of politics associated with grand coalitions are likely to be valued in their own right.

These considerations are clearly related to the rewards of office; no policy considerations enter. Besides facilitating the computation of long-term costs and benefits of alternative strategies, low volatility rates also free politicians from their electoral constraint, enabling them to ignore policy considerations and try to maximize the rewards of office. Therefore, grand coalitions of one kind or another are, if at all, particularly likely to occur in electoral systems having low volatility rates.

Now the question is, which grand coalition will form? Which parties are 'major' and will be included in the coalition, and how will government seats be divided among the allies? These questions have to be settled once parties agree upon a long-term grand coalition, including all major parties. The stability of such an agreement is greatly enhanced when the inherently divisive questions of future allocation of seats and the inclusion or exclusion of certain parties can be settled in an objective way: by applying some simple rules of thumb all parties consider fair beforehand. Proportional representation is a principle which provides such standards. As Lijphart $(1977,39)$ puts it: 'Proportionality, as a neutral and impartial standard of allocation, removes a large number of potentially divisive problems from the decision-making process.' 
This characteristic of the proportionality principle is not merely a matter of the distribution of the payoffs, but touches on essential aspects of coalition formation as well. Proportionality adds to the predictability of the political environment and, as we noted before, the certainty on future benefits is an important factor determining whether or not to opt for grand coalitions at all. We therefore assume that grand coalitions will tend to be formed by applying a rule of proportional representation. "'

Finally, we would like to emphasize that, although the idea of a proportional representation theory stems from our knowledge of Dutch local government coalition behaviour in the past, proportional representation coalitions cannot be considered a mere peculiarity of Dutch folklore. After having completed the penultimate version of this article, we read Steiner's account of coalition behaviour in Switzerland. From 1959 to 1981 Switzerland has known, what Steiner calls, 'magic formula' coalitions. The magic formula on which these coalitions are based is actually nothing else than a rule of proportional representation. What is even more interesting is that Steiner's paper reports an extraordinarily low extent of electoral volatility in Swiss politics (Steiner, 1982, 318-9). The Swiss evidence is completely in line with the predictions of our theoretical model: a low level of electoral volatility induces parties to form grand coalitions based on a proportional representation rule.

\section{COA LITION FORMATION IN DUTCH LOCAL GOVERNMENT}

Before we can start testing our hypotheses it is necessary to outline the institutional structure in which coalition formation in Dutch local government takes place. Furthermore, we have to make a number of additional assumptions that will enable us to apply coalition theory in this setting.

Formally, Dutch local government is headed by the municipal council. The Council of Mayor and Aldermen (which will be abbreviated as CMA from here on) is the executive committee. The CMA is presided over by the mayor, who is appointed by central government. The aldermen are selected by the municipal council from among its members.

In practice the role of the CMA is much more important than that of the council. Students of Dutch local government agree upon the pre-eminence of the CMA over the municipal council. Non-representation of a party on the CMA therefore means that the party lacks an important base of influence on local policies, and forgoes rather prestigious, though not very well-paid, jobs.

The election of aldermen is preceded by negotiations on the CMA's composition: who is going to support whose candidates for aldermanship at the decisive vote? The majority supporting a candidate has to be at least as large as a normal simple majority plus one vote.

In determining the CMA's support on the council we have to make an additional set of assumptions. First, we will assume that only parties represented in the CMA supported the council in the decisive vote. Parties not having aldermen in the CMA are supposed not to support the council and are not considered to be members of the coalition. "

A second additional assumption is needed to enable application of formal coalition theories on our data on Dutch local politics. We have to assume that councilmen belonging to the same party can be considered as one unitary actor. They share the same coalition preferences. This presupposes a certain extent of party discipline. 
Probably the most heroic additional assumptions in our application of coalition theories to Dutch local politics are those with regard to the placement of parties on an ideological (policy) continuum. First, we will have to assume that one ideological dimension, the socio-economic left-right controversy, will adequately account for local party coalition behaviour. Second, we will have to assume (lacking detailed local data) that local branches of the national political parties take the same relative position on this continuum in every municipality. Third, additional assumptions are required to deal with local (independent) parties.

The plausibility of these assumptions regarding party ideologies is hard to evaluate. In as far as evidence on the effect of ideology on coalition behaviour is available, it refers to the level of national, not local, political systems (De Swaan, 1973; Laver and Taylor, 1973).

Research on the salience of the socio-economic left-right dimension in local politics is hard to obtain. Therefore we have to assume that the rank order of local branches of national parties equals the rank order of the national parties on the socio-economic left-right dimension. In other words, we apply one and the same ordering of parties for all municipalities in the Netherlands. No allowance is made for local deviations from this ordering. In our analysis we will order parties on a left-right continuum as illustrated in Fig. 2. This ordering is borrowed from Lucardie (1981). ${ }^{12}$

\begin{tabular}{cccccccc} 
PSP & & & & & & & GPV \\
left & & & & & & RPF \\
& 1 & 2 & 3 & 4 & 5 & 6 & 7 \\
\hline
\end{tabular}

Fig. 2. Ordering of Dutch political parties on a socio-economic left-right scale Source Lucardie, 1981.

Apart from the local branches of national parties, independent parties are represented on municipal councils. Their placement on the left-right scale is highly problematic. The Dutch Bureau of Statistics distinguishes, among other categories, between Roman Catholic-Independent lists, and Independent lists. With regard to the Roman Catholic-Independent lists, we will assume that their position on the left-right scale is identical to that of the national Christian Democratic party (CDA). These lists are concentrated in the southern provinces of the Netherlands where in most municipalities the CDA gains an absolute majority in both national and provincial elections. In local elections the CDA frequently does not participate, for both historic and strategic reasons (for an interesting account of these lists see Dittrich, 1978, 115-20). It is difficult to see, assuming a minimal extent of voter rationality, how these Catholic-Independent lists could take a policy or ideological stance differing radically from the traditional position taken by the CDA.

With regard to the Independent lists, such a solution is not possible. Therefore we removed 53 municipalities, in which an Independent party occupied more than $5 \%{ }^{1.3}$ 
of the council's seats, from our analysis. This means that about $30 \%$ of the municipalities with 20,000 inhabitants and over, could not be included in our analyses. In the municipalities having less than 20,000 inhabitants the phenomenon of Independents and Roman Catholic Independents is virtually ubiquitous. This was one motive for our decision not to include these local authorities in our research. ${ }^{14} \mathrm{Of}$ course, we would have preferred to replace these assumptions with regard to the ideological dimension and the party positions thereon with actual assessments. But this would require extensive and costly research in about 150 municipalities. Resources for such an endeavour were not available.

\section{TESTS OF THEORIES OF COALITION BEHAVIOUR}

We earlier formulated three hypotheses specifying the relevance of different coalition theories under different political conditions. These hypotheses, to repeat, were:

(1) The predictive value of theories based on the size principle is highest in nationalized high-volatility electoral systems.

(2) The predictive value of theories based on the minimization of ideological distance is highest in localized high-volatility elections.

(3) The predictive value of theories based on proportional representation is highest in low-volatility electoral systems.

If these tendencies are to add up to a successful conditional theory of coalition behaviour, the combined performance of the best performing size theory in nationalized high-volatility elections of policy-range theory in localized high-volatility systems, and of the most adequate variant of proportional representation theory in low-volatility electoral systems, should be considerably better than the predictive value of traditional coalition theories predicting coalition behaviour irrespective of local political conditions. Of course, from the point of view of theoretical parsimony these latter theories are preferable. But if the predictive value of our conditional model is higher than these more simple unconditional hypotheses one would probably prefer this model on these grounds.

The results of this test, based on a procedure developed by De Swaan (1973) and Laver and Taylor (1973), are shown in Table I. The test procedure described in detail in the Appendix - yields a test statistic, V. The larger the V, the higher the predictive value of a theory.

The first result of our analyses, not reported extensively here, was that none of the unconditional theories offered statistically significant test results. This makes a test of our conditional theory all the more interesting. Will this model do better than the unconditional alternatives and provide statistically significant results? Comparing results of our conditional theory with those of the best predicting unconditional theory, proportional representation (D'Hondt variant) theory has disappointing results. With regard to both the percentage of predictive successes and the test statistic $\mathrm{V}$, the unconditional model is clearly superior. So both on grounds of predictive adequacy and on grounds of theoretical parsimony, proportional representation theory seems to be a better (though not satisfactory) model for the explanation of coalition behaviour in the Netherlands than our conditional model. 
TABLE I. Test results of a conditional model of coalition formation compared with the best performing simple unconditional theory (data from Dutch municipalities with 20,000 inhabitants or more in 1982)

\begin{tabular}{|c|c|c|c|}
\hline \multirow[b]{2}{*}{ System type* } & \multicolumn{2}{|c|}{ Results conditional theory } & \multirow[b]{2}{*}{$\begin{array}{l}\text { Value of test } \\
\text { statistic } V_{1} \\
\text { and } \\
\text { its critical } \\
\text { value (between } \\
\text { brackets) }\end{array}$} \\
\hline & $\begin{array}{l}\text { Coalition } \\
\text { strategy } \\
\text { (predicted to } \\
\text { be appropriate } \\
\text { in a system } \\
\text { type) })^{\dagger}\end{array}$ & $\begin{array}{l}\% \text { and number } \\
\text { (in } \\
\text { brackets) of } \\
\text { predictive } \\
\text { successes }\end{array}$ & \\
\hline $\begin{array}{l}\text { Nationalized } \\
\text { high volatility } \\
\left(N_{i}=24\right)\end{array}$ & $\begin{array}{l}\text { Minimum number } \\
\text { of parties }\end{array}$ & $\begin{array}{l}21 \% \\
(5)\end{array}$ & $\begin{array}{l}11.989 \\
(35.8)\end{array}$ \\
\hline $\begin{array}{l}\text { Localized } \\
\text { high volatility } \\
\left(\mathrm{N}_{\mathrm{i}}=15\right)\end{array}$ & $\begin{array}{l}\text { Policy range } \\
\text { minimization }\end{array}$ & $\begin{array}{l}40 \% \\
(6)\end{array}$ & $\begin{array}{l}15.706 \\
(55.2)\end{array}$ \\
\hline $\begin{array}{l}\text { Low volatility } \\
\left(\mathrm{N}_{\mathrm{i}}=61\right)\end{array}$ & $\begin{array}{l}\text { Proportional } \\
\text { representation } \\
\text { D'Hondt variant }\end{array}$ & $\begin{array}{l}57 \% \\
(35)\end{array}$ & $\begin{array}{c}93.530 \\
(133.4)\end{array}$ \\
\hline $\begin{array}{l}\text { Over-all } \\
\text { performance of } \\
\text { conditional } \\
\text { theory } \\
\left(\Sigma \mathrm{N}_{\mathrm{i}}=100\right)\end{array}$ & & $\begin{array}{l}46 \% \\
(46)\end{array}$ & $\begin{array}{l}121.225 \\
(214.5)\end{array}$ \\
\hline $\begin{array}{l}\text { All } \\
(\mathrm{N}=100)\end{array}$ & $\begin{array}{l}\quad \text { Results of } b \\
\text { Proportional } \\
\text { representation } \\
\text { D'Hondt variant }\end{array}$ & $\begin{array}{l}\text { nconditional theo } \\
56 \% \\
(56)\end{array}$ & $\begin{array}{l}169.771 \\
(214.5)\end{array}$ \\
\hline
\end{tabular}

*For the construction of our typology of electoral systems see section 2.

†For a short description of these coalition strategies see footnotes 1,2 and 10.

$¥$ For details on the test procedure see the appendix; $\alpha=20 \%$, one-tailed.

\section{CONCLUSION}

No doubt several qualifications could and, to be sure, should be made regarding the tests of these theories. Some rather demanding operational assumptions had to be made. Furthermore, the nature of the test performed here was rather conservative, as compared with the tests conducted by Laver and Taylor (1973) and De Swaan (1973). ${ }^{15}$ Maybe in future research some of these assumptions could be relaxed and a more lenient test applied.

Though the tests performed here are no doubt susceptible of improvement, it may nevertheless be worth while to have a more detailed look at our results. Should these results be completely unintelligible, then the model probably will have to be discarded altogether as being essentially a cul-de-sac.

In our theoretical model a fourfold classification of local political systems was proposed. Using the same model, however, a twofold categorization would also have been justifiable. We earlier set out a model in which it was assumed that the behaviour of politicians (also with regard to coalition formation) was influenced by 
TABLE II. Test results of seven unconditional coalition theories in different electoral system-types (data from Dutch municipalities with 20,000 inhabitants or more in 1982)

\begin{tabular}{|c|c|c|c|}
\hline $\begin{array}{l}\text { Coalition } \\
\text { theory* }\end{array}$ & $\begin{array}{l}\text { System typet } \\
\text { (in each column: } \\
\text { and value of test } \\
\text { Localized high- } \\
\text { volatility } \\
\text { systems }\end{array}$ & $\begin{array}{l}\text { edictive successes } \\
\left.V_{\mathrm{i}}\right)^{\ddagger} \\
\text { Nationalized } \\
\text { high-volatility } \\
\text { systems }\end{array}$ & $\begin{array}{l}\text { Low-volatility } \\
\text { systems }\end{array}$ \\
\hline Minimum winning & $\begin{array}{l}47 \% \\
9.734\end{array}$ & $\begin{array}{l}21 \% \\
7.018\end{array}$ & $\begin{array}{l}33 \% \\
27.168\end{array}$ \\
\hline Minimum weight & $\begin{array}{l}33 \% \\
10.811\end{array}$ & $\begin{array}{l}4 \% \\
1.386\end{array}$ & $\begin{array}{l}23 \% \\
26.402\end{array}$ \\
\hline $2 / 3$ criterion & $\begin{array}{l}47 \% \\
9.288\end{array}$ & $\begin{array}{l}21 \% \\
5.787\end{array}$ & $\begin{array}{l}34 \% \\
25.503\end{array}$ \\
\hline $\begin{array}{l}\text { Minimum number } \\
\text { of parties }\end{array}$ & $\begin{array}{l}33 \% \\
8.753\end{array}$ & $\begin{array}{l}21 \% \\
11.989\end{array}$ & $\begin{array}{l}33 \% \\
37.999\end{array}$ \\
\hline $\begin{array}{l}\text { Minimization of } \\
\text { policy range }\end{array}$ & $\begin{array}{l}40 \% \\
15.706\end{array}$ & $\begin{array}{l}21 \% \\
13.268\end{array}$ & $\begin{array}{l}26 \% \\
29.619\end{array}$ \\
\hline $\begin{array}{l}\text { Proportional } \\
\text { representation } \\
\text { D'Hondt variant }\end{array}$ & $\begin{array}{l}33 \% \\
20.268\end{array}$ & $\begin{array}{l}67 \% \\
55.973\end{array}$ & $\begin{array}{l}57 \% \\
93.530\end{array}$ \\
\hline $\begin{array}{l}\text { Proportional } \\
\text { representation } \\
\text { straight quota }\end{array}$ & $\begin{array}{l}40 \% \\
23.041\end{array}$ & $\begin{array}{l}54 \% \\
43.424\end{array}$ & $\begin{array}{l}49 \% \\
83.210\end{array}$ \\
\hline $\begin{array}{l}\text { Number of cases } \\
\text { Critical value } \mathrm{V}_{\mathbf{i}} \\
(\alpha=20 \%, 1 \text {-tail })\end{array}$ & $\begin{array}{l}15 \\
35.8\end{array}$ & 55.2 & 133.4 \\
\hline
\end{tabular}

* For a short description of these coalition principles see footnotes 1,2 and 10 .

$\uparrow$ For the construction of our typology of electoral systems see section 2 .

$\ddagger$ For details on test procedure see the appendix.

the presence/absence of an electoral constraint. Once such a constraint is operative, politicians have to compete for the electorate's vote. From this perspective a twofold classification seems natural: systems where an electoral constraint is operative, as in localized high-volatility systems, and systems where this is not the case, as in both nationalized high-volatility and both types of low-volatility electoral systems. In the localized high-volatility systems, politics is likely to be competitive, while in the other systems it is probably less or not competitive.

The data in Table II appear to validate this dichotomy of local competitive versus other systems. First, it is evident that coalitions of the proportional representation type are found relatively more often in nationalized high-volatility and low-volatility elections than in localized high-volatility (competitive) electoral systems (hypothesis 3 ). Second, most of the theories predicting coalitions based on the exclusion of one or more major parties seem to fare better (though not always very much) in localized high-volatility than in the other municipalities. This is partially in line with hypotheses 1 and 2 . 
This partial and weak corroboration of our theoretical model poses two problems, however. The first question to be asked is: Why is policy-range theory not performing better than the minimum-size theories? Here two factors may be at play. First there has been, in recent years, a relative convergence of the liberal conservative (VVD) and the Christian-Democratic (CDA) parties. Perhaps this convergence went so far that for the third major party (the social democrats) a choice between either parties became a matter of tweedledee and tweedledum. Second, the questionable adequacy of some assumptions (pre-eminence everywhere of socioeconomic issue dimension and no local deviations from the national ordering of parties on that dimension) may have impeded the predictive power of policy-range theory.

The second question to be asked is why minimum-size theory is performing badly and proportional representation theory relatively well in nationalized high-volatility electoral systems. Apparently, the hypothesized effect of volatility on the willingness of parties to adopt long-term strategies does not occur, or is not strong enough to affect the coalition behaviour of parties. The size of fluctuations in the voting shares of parties in systems characterized as highly volatile does not seem to be as large as to let high volatility be an important determinant of uncertainty on the future benefits of grand coalitions. With the wisdom of hindsight it might be argued that grand coalitions in electorally turbulent environments offer parties some insurance against electoral windfalls and other threats to their participation in the governmental coalition.

Our data suggest that in electoral systems lacking competition, political parties are more likely to opt for co-operative strategies, than in systems where politicians are forced to compete. This points to a basic parallel between the behaviour of parties in the political market and firms in the economic market. In either setting the competitiveness of a market is closely related to the collusion of entrepreneurs.

A cautious conclusion can now be formulated. Apparently, coalition behaviour varies with the competitiveness of the local political arena. In nationalized highvolatility and low-volatility electoral systems where the electoral constraint and the urge to compete are absent, coalition behaviour acquires, relatively often, the character of co-operation in a grand coalition (based on proportional representation). Coalition behaviour based on the exclusion of major parties, however, is not very frequently found in these settings, while it is found more often in localized high-volatility (competitive) electoral systems.

Though our conditional theory as such proved inadequate in its predictions, a more detailed look at our data showed that some interesting differences in the performance of coalition theories occurred under conditions that, according to our model, would be relevant for coalition behaviour. These differences, moreover, were at least partially in line with what might have been expected from our model.

These findings, in our view, suggest that in the development of a more adequate and general coalition theory, the notion of a conditional model (different coalition strategies apply under different conditions) may play an important role. Furthermore, our findings indicate that in future theoretical and empirical work on coalition behaviour it may be worth while to pay attention to the competitiveness of party politics as a relevant condition. 


\section{NOTES}

1 For a detailed review of formal coalition theories see De Swaan (1973). Coalition theories dealt with here all assume that only coalitions commanding at least a majority (winning coalitions) of seats in the legislative council will be formed. Size-principle theories predict coalitions of minimum size. Size theories differ in definitions of size. Minimum winning theory predicts that no coalitions containing unnecessary actors will be formed. A party is considered unnecessary if it can be excluded from the coalition without making that coalition nonwinning. Another variant of size theory predicts that only coalitions of a minimum number of parties will be formed. In minimum weight theory the formation of coalitions commanding a minimum number (though still a majority) of seats in the legislative council is predicted. A variant on minimum weight theory, the two-thirds-criterion proposition, predicts, allowing for effects of uncertainty, only coalitions of relatively modest (commanding up to $67 \%$ of the seats) majorities. These four theories will be tested later.

2 These theories assume that parties can be ordered on an ideological continuum. The coalition having a minimum range (between the leftmost and rightmost party in the coalition) on that continuum will be formed. For details on the concept of range and the comparison of ranges. see De Swaan, 1973, 92. In our tests of these theories, we followed this author in these matters. In our tests of policy-range theory we tested one variant only, one allowing for both minimum-range coalitions containing unnecessary parties and coalitions without such parties.

3 Another dimension of political competition is political concentration. This multidimensional view upon competition is also found in economic literature: see for instance Stigler, 1983, 34. The term 'volatility is borrowed from Pedersen (1983). Our index is closely related to the indicator proposed by Pedersen. The degree of electoral volatility is defined as the average of the absolute inter-election differences between the voting shares of particular blocs of political parties in the 1970, 1974 and 1978 municipal elections (data on the 1982 elections are not yet available). The formula is

$$
E F I=\frac{\sum_{i=1}^{n}\left|P_{i, 1970}-P_{i, 1974}\right|+\left|P_{i, 1474}-P_{i, 1978}\right|+\left|P_{i, 1970}-P_{i, 1978}\right|}{18}
$$

$$
\text { in which } P_{i, 14 . .}=\text { voting share of party bloc } \mathrm{i} \text { in } 19 . \text {. }
$$

For the purpose of calculating the index we distinguished six blocs, extreme right (BP, BR, SGP, GPV), liberal (VVD, DS'70). Christian-Democratic (CDA, KVP, ARP, CHU, Roman Catholic Independents. PCG. PC and CCP), Centre-left (PvdA, PAK and D'66), extreme left (PPR, PSP and CPN), and Independents. Data on blocs were used in order to enhance inter-temporal comparisons. For obvious reasons our index reflects only net changes in voting shares. For our purposes this is acceptable, since this index in our model functions as a criterion upon which local politicians base the judgment on the presence or absence of an electoral constraint. Most local politicans will not have information on gross fluctuations.

4 In order to establish the degree of nationalization of local election results we computed the national average inter-election mutations of the voting shares of the party blocs used earlier in the computation of the index of electoral volatility. These averages were computed over all municipalities having 20,000 inhabitants or more. Then our index of nationalization of elections was computed as:

$$
\begin{aligned}
& N I=\frac{\sum_{i=1}^{6}\left|P_{i, 70-74}-N_{i, 71-74}\right|+\left|P_{i .711 .78}-N_{i .71-78}\right|+\left|P_{i .74-78}-N_{i .74-78}\right|}{\sum_{i=1}^{6}\left|P_{i .1970}-P_{i .1974}\right|+\left|P_{i .1974}-P_{i .1978}\right|+\left|P_{i .1970}-P_{i .1978}\right|} \\
& \text { in which } P_{i, 19} \text {. = voting share of party bloc } i \text { in } 19 . \\
& P_{i, 7.7 .}=\left(P_{i, 197 .}-P_{i, 197 .}\right) \\
& \mathbf{N}_{\mathrm{i}, 19 . .}=\text { national average voting share of party bloc } \mathrm{i} \text { in } 19 . \\
& \text { in all municipalities with more than } 20,000 \text { inhabitants } \\
& N_{i, 7,-7 .}=\left(N_{i, 197 .}-N_{i, 197 .}\right)
\end{aligned}
$$


This index equals 1 when local election results perfectly mirror national trends. The smaller NI becomes, the more important are local deviations from these national averages.

5 We considered an EFI score of 4.594 or higher as a high rate of volatility, and a score of 4.593 and below as a low or medium rate of volatility. Furthermore an NI score of 1 to 0.172 was considered as a high degree of nationalization, a score of 0.171 and below, as a medium or low degree of nationalization. These cutting points were chosen to coincide with the variable means (EFI mean: 4.594; NI mean: 0.171).

6 Coalitions in Dutch local government were traditionally based on a principle of proportional representation. In the late 1960 s and 1970 s a new form of coalition formation gradually became more popular. These new coalitions were based on the exclusion of one or more major parties and or programmatic negotiations between parties. Research into this new phenomenon was done by Wolters (1976) and Tops and Korsten (1984). In this article we will see whether these 'new' coalitions are of a minimum size or of minimal policy range, and under what conditions coalitions excluding major parties are likely to occur.

7 We are indebted to Nico Mol for his suggestion to include the notion of supergames in this context. Of course, the sole responsibility for its application rests with the author.

8 Another factor, of course, is the rate of discount on future benefits. Here we will assume that politicians use the same discount rate under all circumstances and that it is not so high as to preclude long-term strategies. Furthermore, we assume, for the sake of simplicity, that all politicians value a specified number of seats in government equally.

9 Of course, the number of Cabinet ministers or aldermen may be increased, but this reduces the average weight of these positions.

10 We actually used two rules of proportional representation. The well-known D'Hondt method and a straight quota system using greatest remainders as means of allocating any remaining seats. The D'Hondt method tends to yield coalitions of fewer parties than the greatest remainders method. Both variants were tested against our data.

11 This raises two problems. First, this assumption is completely inadequate in the small municipalities. Here there are only two aldermen, and in the fractionalized Dutch party system, it is often impossible to compose a CMA supported (in the strict operational sense proposed here) by a majority of the council. This is one of the reasons for confining our analysis to municipalities having 20,000 or more inhabitants. Making this assumption implies that we ignore the possibility that parties having no aldermen in the CMA support it because the mayor is a party member. Empirical evidence in this respect is scarce and based only on a survey of mayors from the sociodemocratic party. This survey, however, seems to support this assumption (Wolters, 1976, 53). Furthermore, parties having less than $5 \%$ of the seats (one in municipalities with less than 70,000 inhabitants and two or less in authorities with more than 70,000$)$ were not considered players in the coalition game. They cannot enter coalitions or support them. This assumption was made in order to facilitate our computations that had to be performed with the help of a desk calculator only.

12 Lipschits's (1969) ordering is identical, apart from minor details due to later developments in Dutch politics. Castles and Mair $(1984,80)$ reported essentially the same ordering based on a questionnaire survey of nine leading Dutch political scientists. Furthermore it can be noted that in a mass survey Van der Eijk and Niemöller $(1983,247-50)$ find that when electors are asked to order parties along a left-right scale they too are constructing this ordering.

13 See note 11 .

14 See note 11 , for another reason.

15 See appendix for further details.

\section{APPENDIX: STATISTICAL TEST}

The test of significance used here is closely related to tests employed by De Swaan (1973, appendix by Mokken) and Laver and Taylor (1973). In these tests it is assumed that the coalition actually formed is randomly selected from the set of coalitions that can be formed in a particular situation. Here we assume, following De Swaan and Mokken $(1980,203)$, that only majority coalitions are to be considered elements of the set of all possible coalitions. Using the binomial distribution the probability of a successful prediction of theory $T$ assuming randomness, and sampling without replacement, is:

$$
P=\left(\begin{array}{c}
G \\
S
\end{array}\right)\left(\frac{Q}{C}\right)^{S}\left(1-\frac{Q}{S}\right)^{G-S}
$$


in which $G=$ number of coalitions formed in situation $i=1$

$S=$ the number of successful predictions by theory $T$ (either 0 or $\mathrm{I}$ )

$\mathrm{Q}=$ the number of coalitions predicted by theory $\mathrm{T}$

$\mathrm{C}=$ the number of possible majority coalitions in situation $\mathrm{i}$.

$\mathrm{G}=1$, and $\mathrm{S}$ is either 0 or 1 , because we considered only the first coalition formed $\mathrm{n}$ the 1982-6

period.

Since we want a general evaluation of a theory and no evaluation which is limited to one situation only (as in formula 1), test results have to be aggregated one way or another. Both Laver and Taylor (1973) and De Swaan (1973) propose to sum the results of these $\mathrm{K}$ independent tests in the following way:

$$
\mathrm{V}_{\mathrm{i}}=\ln \left(\mathrm{p}_{\mathrm{i}}\right)
$$

$$
\begin{aligned}
& \text { in which } \ln \left(p_{i}\right) \text { is the natural } \\
& \text { logarithm of } p_{i} \text {. }
\end{aligned}
$$

This test statistic $\mathrm{V}$ is approximately chi-square distributed with $2 \mathrm{k}$ degrees of freedom. Laver and Taylor correct this statistic for continuity. Since we are not interested in the exact probability of the test results we did not use such a correction (De Swaan and Mokken, 1980, 205).

The test performed here is very conservative indeed. First because we did not use the correction for continuity (see De Swaan and Mokken, 1980,211). but also because of the stringency of our actor criterion (here: $5 \%$; Laver and Taylor, $1 \%$ and De Swaan and Mokken 2.5\%). Since thereby we declare a number of parties as 'non-existent' in the coalition game, the number of possible coalitions decreases. Inspection of equation (1) shows that this number is determining $P$ and thereby the test statistic $\mathrm{V}$. Because of the conservativeness of this test we employed a rather lenient ( $\alpha=20 \%$. one-tailed) parameter.

Finally, it is important to note that this test procedure is not used in order to generalize any findings (we used data from total population). This test is used as a rather arbitrary criterion to evaluate the different theories proposed.

\section{REFERENCES}

Breton, A. (1974). The Economic Theory of Representative Government. Chicago: Aldine.

Castles, F. G. and Mair, P. (1984). 'Left-right political scales some "expert" judgments', European Journal of Political Research 12, 73-88.

Dittrich, K. L. L. M. (1978). Partypolitieke verhoudingen in Nederlandse gemeenten, een analyse van de gemeenteraadsverkiezingen 1962-1974, University of Leiden, Ph.D. thesis.

Downs, A. (1957). An Economic theory of Democracy. New York: Harper \& Row.

Dunleavy, P. (1980). Urban political analysis. London: Macmillan.

Eijk, C. van der and Niemöller, B. (1983). Electoral change in the Netherlands. University of Amsterdam, Ph.D. thesis.

Frey, B. and Lau, L. J. (1968). 'Towards a mathematical model of government behaviour', Zeitschrift für Nationalökonomie 28, 355-80.

Laver, M. and Taylor, M. (1973). 'Government coalitions in Western Europe', European Journal of Political Research 1, 205-48.

Lijphart, A. (1977). Democracy in plural societies. New Haven and London: Yale University Press.

Lijphart, A. (1979). Verzuiling, pacificatie en kentering in de Nederlandse politiek. Amsterdam: J. H. de Bussy.

Lipschits, J. (1969). Links en rechts in de politiek. Meppel: Boom.

Lucardie, A. P. M. (1981). 'Politieke Partijen', in Andeweg, R., Hoogerwerf, A. and Thomassen, J., eds. Politiek in Nederland, 61-78. Alphen aan den Rijn: Samsom.

Pedersen, M. N. (1983). 'Changing patterns of electoral volatility, 1948-1977: Explorations in explanation', in Daalder, H. and Mair, P., eds, Western European party systems: continuity and change, 29-66. Beverly Hills: Sage.

Steiner, J. (1982). 'Switzerland: Magic formula coalitions', in Browne, E. C. and Dreijmanis, J., eds, Government coalitions in western democracies, 315-34. London: Longman.

Stigler, G. J. (1983). The organization of industry. Chicago: University of Chicago Press.

Swaan, A. De (1973). Coalition formation and cabinet formations a study of formal theories of coalition formation as applied to nine European parliaments after 1981. University of Amsterdam. Ph.D. thesis. 
Swaan, A. De and Mokken. R. J. (1980). 'Testing coalition theories: The combined evidence', in Lewin. L. and Vedung, E., Politics as rational action, 199-214. Dordrecht: Reidel.

Taylor, M. (1976). Anarchy and cooperation. London: Wiley.

Tops, P. W. and Korsten, A. (1984), Beeld en werkelijkheid: Collegevormen in Nederlandse gemeenten (1970-1982). Amsterdam: Kobra.

Wolters, M. (1976). Kollegevorming en polarisatie. Amsterdam: Wiardi Beckmanstichting. 